
UTHOR'S ABSTRACT' OF THIS PAPER ISSUED BY THE BIBLIOGRAPHIC SERVICE, OCTOBER 27

\title{
THE COURSE OF THE WOLFFIAN TUBULES IN MAMMALIAN EMBRYOS
}

\author{
FREDERIC T. LEWIS \\ Harvard Medical School, Boston, Massachusetts \\ THIRTEEN FIGURES
}

In early stages, when the Wolffian tubules are so short that they may be cut throughout in single sections, their course from glomerular capsule to Wolffian duct has been thoroughly studied. Kölliker, Mihalkovics, Meyer, Schreiner, and others have described their S-shaped form. But in older embryos the length and sinuosities of the tubules are such as to require reconstruction. "Nevertheless," as Nicolas wrote in 1891, "it can be recognized without too great difficulty that their general orientation has remained unchanged - they have merely elongated and folded capriciously in different planes." The idea of capricious folds is well illustrated in the single reconstruction of a tubule from a human embryo of $10.2 \mathrm{~mm}$., published by Kollmann, and many times reproduced. But Felix records that he has "studied two hundred models of mesonephric tubules from the most different stages of development," and in none of them has he found "any coiling of the tubule." Consequently he infers that Kollmann's model must represent 'a very exceptional rarity' - a conservative and accurate conclusion. The only change observed by Felix after the tubule has become S-shaped occurs near the junction of the middle and distal segments of the $\mathbf{S}$ (distal meaning toward the Wolffian duct), and consists in the formation of "a loop directed either cranially or caudally." Unfortunately Felix has not figured in detail any of the late stages included among the two hundred tubules modeled, presumably from human embryos, so that Kollmann's drawing appears to occupy the field alone. 
In the pig the tubules are more highly developed than in man. They have been carefully studied by MacCallum, and are shown in two published reconstructions which seem to reveal more than is brought out in the accompanying text. Taken in connection with two models now in the Harvard Laboratory, they indicate that there is a pattern in the Wolffian tubule of the pig, quite as definite and interesting as that of the metanephric or renal tubule. Although a larger number of tubules should be modeled to establish this conclusion and to show the range of variation, the following interpretation of the somewhat laborious work already done may be of value. A simple pattern for the human tubules, and a more complex one-for those of the pig, will be presented, showing how both may be derived from a common origin, one by simplification and the other by elaboration.

Omitting from consideration the transformation of the primary vesicle, we may begin with the S-shaped stage which was well described, and perhaps for the first time, by Kölliker in 1879. Referring to a rabbit embryo somewhat older than that here shown in figure 1 , he writes:

"From the Wolffian duct there arises first a very slender tubule which passes medially along the dorsal side of the Wolffian body, clear across the organ; then, making a loop, it bends upon itself and retraces its course to the lateral side; finally, after a third coil, it ends in the Malpighian corpuscle, medially placed on the ventral side." He disposes of the later stages as follows: "These three chief coils become complicated by the formation, at the places where the bends occur, of accessory coils in different planes, so that finally the course of a single tubule becomes so complicated that it cannot be unravelled in sections."

That the young tubules have the form of a letter S was further established by Mihalkovics in 1885, from studies of the lizard, duck, chick, and sheep. Beginning as a detached vesicle, the tubule becomes cupped or crescentic, with the glomerulus developing within its concarity. It then takes the form of a 'ladle' or 'sickle,' as a short handle is marked off, joining the Wolffian duct. This stage, as Mihalkovies found, gives place to the S. He considered that the distal limb of the S could be set apart as the tubulus collectivus and that at the region of the distal bend it became dilated and coiled, forming a tubulus secretorius, but 
to these designations Nicolas and Von Winiwarter have taken exceptions.

Of greater interest perhaps, and not open to question, is the finding by Mihalkovics that in the sheep the middle or transverse limb of the S elongates and becomes itself S-shaped, though the long axis of the second $\mathrm{S}$ is horizontal, being at right angles with that of the first. "Here in a narrow space," according to Mihalkovics, "a winding-up process takes place," which leads to a double or reversed spiral, as shown in figures 3 and 4. Mihalkovics did not follow the further development of this pattern.

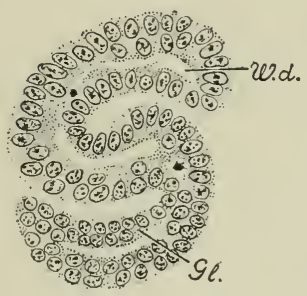

$\mathcal{F}_{\text {ig. }}$.

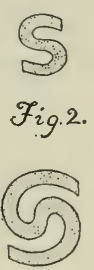

Fig.3.

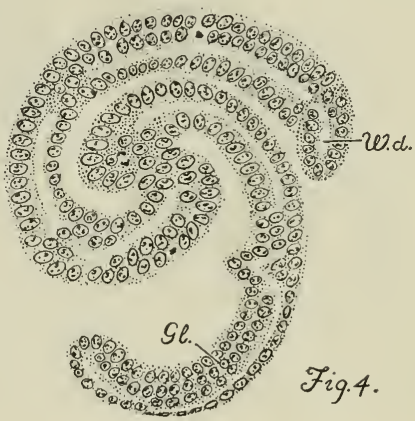

Fig. 1 Section of an S-shaped Wolffian tubule. Rabbit embryo, $10 \frac{1}{2}$ days, $5.4 \mathrm{~mm}$. Harvard Embryological Collection, series 560, sections 158-161. $\times 200$.

Fig. 2 Diagram of the S-shaped tubule.

Fig. 3 Diagram of the double-spiral tubule.

Fig. 4 Section of a double-spiral tubule. Pig embryo, $4.5 \mathrm{~mm}$. Harvard Embryological Collection, series 1404, sections 114-115. $\times 200$.

$G l$., glomerular capsule; W.d., Wolffian duct.

In 1890 Meyer described the simple S-stage in man, and in 1902, with a wealth of lithographs, Schreiner repeated the observations of Mihalkovics on the early stages in the lizard, duck, and chick, with the rabbit in place of the sheep. He refers to the double spiral pattern as a 'much-coiled S,' but there is nothing to suggest that he regarded it as a particularly significant form, essentially different from the simple S. Minot, in 1892, in an account based upon Mihalkovics, notes that the tubules of amniota "retain for some time their simple S-shape, although the curves of the S become more and more exaggerated." These appear to be the 

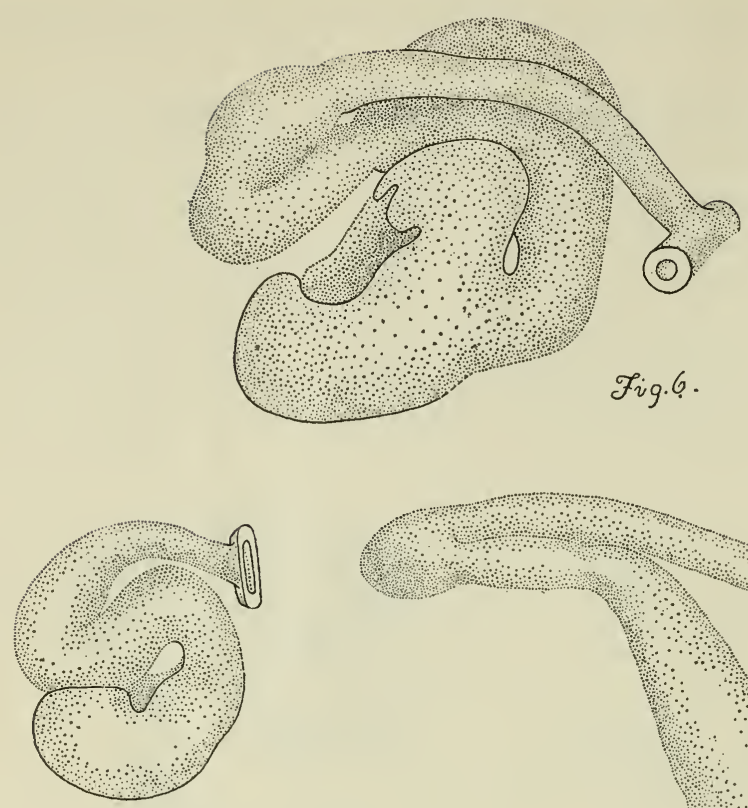

$\mathcal{F}_{i g .5}$.

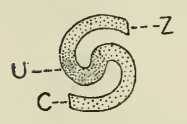

$\mathscr{F}$ ig. 8 .
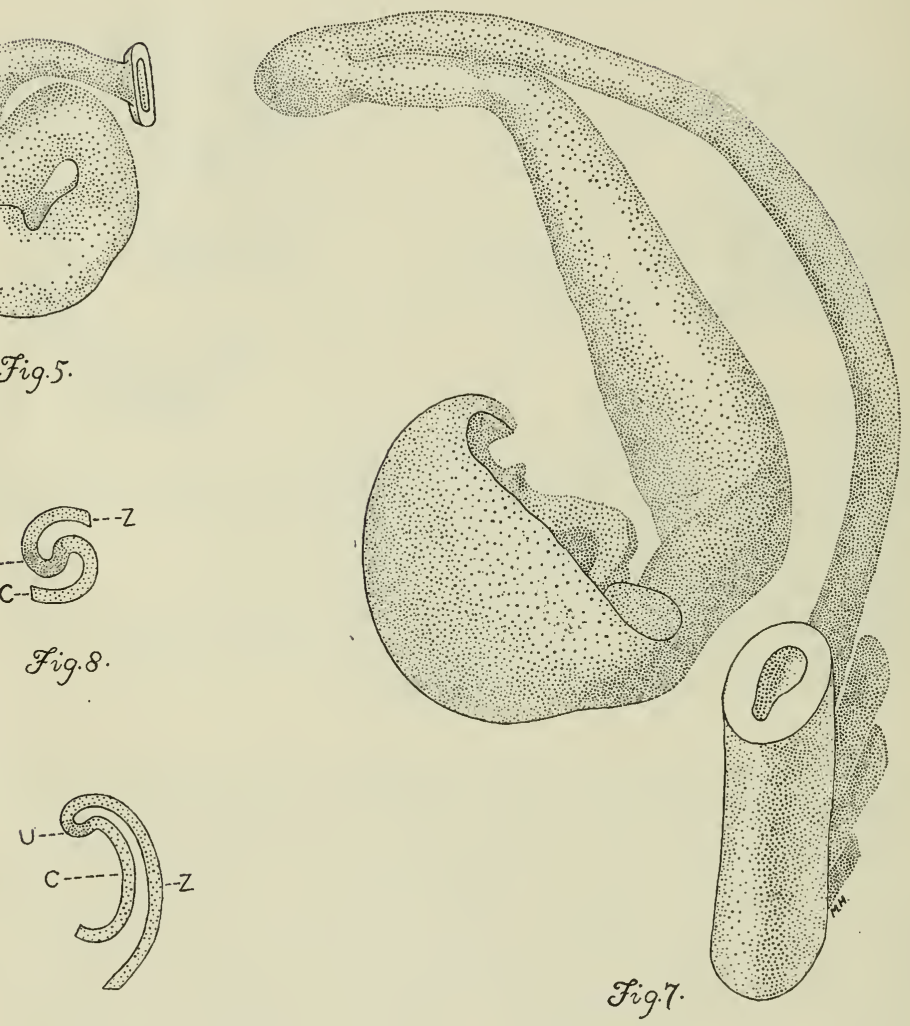

Fig. 9 .

Figs. 5 to 7 Models of Wolffian tubules in human embryos. $\times 175$ (approximately). 
principal references to the double spiral which follows the simple $\mathrm{S}$ and which is here regarded as the common origin of the later patterns and the key to their interpretation.

A suitable designation for the form which we have called a double spiral (fig. 3) is unfortunately not available. It is a shape which occurs at the apex of the coil of large intestine in the pig, where some of its interesting properties have been discussed by Lineback, and it may perhaps be found elsewhere. Impressed with Thompson's application of mathematics to biological problems, the aid of a mathematician was sought in describing the form in figures 3 and 4 , and in determining what factors of growth might account for the regular transformation of the simple $\mathrm{S}$ into the double spiral. There are, however, so many unknown factors in the nature of the surrounding medium, which may keep the growing coil within a circular area, and in the physical nature and method of expansion of the tube-wall itself, that a mathematical interpretation was not forthcoming, and the problem was returned as 'biological.' It may be noted that mitotic figures are rather evenly distributed, and that no evidence is found to support the idea of Mihalkovics that a special elongation of the middle segment in cramped quarters produces the double spiral. In fact, if the middle portion remains short and the two ends of the simple $\mathrm{S}$ elongate, continuing their respective curves, the double spiral will result, though the axis of the figure rotates. In the shifting position of the Wolffian duct in later stages, there is clear evidence that such a curved elongation of the distal segment actually takes place.

In human embryos the simple $\mathrm{S}$ may be expected in 6-mm. specimens and in those somewhat smaller. At $7.5 \mathrm{~mm}$. the double spiral has formed, as shown in the model, figure 5. The tubule chosen was one in which the essential bends fell within the plane of section, thus lessening the chance of distortion in the process of modeling. The liberty has been taken of showing the tubule reversed in the figure, as if it belonged to the left Wolffian body, to facilitate comparison with other models. Ex-

Fig. 5 Embryo of $7.5 \mathrm{~mm}$. Harvard Embryological Collection, series 256, sections 471-485.

Fig. $616.0 \mathrm{~mm}$. Harvard Embryological Collection, series 2044, sections 1045-1067.

Fig. $722.8 \mathrm{~mm}$. Harvard Embryological Collection, series 871, sections 887-908.

Fig. 8 Diagram of the double-spiral stage, shown in figure 5, with its subdivision into segments $\mathrm{C}, \mathrm{U}$, and $\mathrm{Z}$.

Fig. 9 A corresponding diagram of the stage shown in figure 7. 
cept for reversal, no difference in shape could be observed between the tubules of the opposite sides. The embryo shows thirty-four tubules entering the right Wolffian duct, which is the number credited to this specimen in Doctor Bremer's earlier study. On the left there are thirty-seven tubules, including four of somewhat retarded development at the caudal end. Beginning the count anteriorly, the tubule modeled is the twentyseventh. As calculated from the model, which was made at an enlargement of 500 diameters, the length of the tubule from glomerular capsule to Wolffian duct is $0.3 \mathrm{~mm}$.

For purposes of description this double-spiral tubule may be divided into three parts, as shown in the diagram, figure 8 . Beginning with the capsule, there is a portion which may be designated $C$, this letter suggesting its shape. It curves laterally and dorsally and passes into the lateral arm of a portion named $U$, the letter again suggesting the form. Finally, the medial limb of the part $U$ ends in another simple C-shaped curve, which, as it is the terminal portion, may be designated $Z$. This swings laterally to end in the Wolffian duct which at this early stage is both lateral and dorsal. The rather cumbersome subdivision of the tube into $C, U$, and $Z$ portions will prove especially serviceable in the more complicated later stages in the pig embryo.

The second model of a human tubule (fig. 6) is from an embryo of $16 \mathrm{~mm}$., excellently preserved and stained with iron haematoxylin. The tubule selected is from the left Wolffian body, in which there are thirty tubules entering the Wolffian duct, this one being the eighteenth. Presumably it has passed through a stage similar to that in figure 5, but has increased in length from $0.3 \mathrm{~mm}$. to $0.8 \mathrm{~mm}$. Although cytological differentiation has advanced, the coiling of the tubule has undergone a slight retrograde movement. Beginning at the glomerular capsule, there is a somewhat constricted neck, as others have frequently noted, and portion $C$ is recognized as the tubulus secretorius of Mihalkovics or tubulus postglomerularis of Nicolas. It is capacious, with wide lumen, and thick walls composed of somewhat elongated cells distinctly marked off from one another. These cells have conspicuous terminal bars, a frayed brush- 
border, a superficial granular zone not deeply stained, and a still paler basal zone containing the oval nuclei. In a typical manner they show the histological features of secretory activity which cannot be reconciled with Gadow's opinion that "the Wolffian body in birds and mammals appears never to function, not even in the embryo."1

In the $16-\mathrm{mm}$. embryo, the segment $U$ may be considered to begin where the tubule becomes abruptly narrower, with a corresponding radical change in the histological nature of its walls. The lumen is narrower, and the cells which are longer, with less cytoplasm, stain deeply with iron haematoxylin. The portion $U$ is therefore a subdivision of the tubulus collectivus of Mihalkovics or tubulus terminalis of Von Winiwarter. Whatever its function, it must be very different from that of the preceding part. With certain minor swellings and constrictions, the portion $U$ makes the bend and passes gradually into $Z$. As the Wolffian duct shifts ventrally, this terminal part of the tube has become longer and more curved. Sometimes, as noted by Felix, it does not remain in the same horizontal plane with the rest of the tubule, but may bend either anteriorly, as in the figure, or posteriorly.

In an older embryo-22.8 mm., figure 7 -certain tubules are much longer than before, though degeneration of the Wolffian body has become active. Felix found that from the stage of $21 \mathrm{~mm}$. onward, the Wolffian tubules are "almost all broken in one or several places," notably at the neck of the glomerular capsule, at the junction of the secreting and collecting portions, and at the outlet into the Wolffian duct, and that "all degenerating tubules show a tendency to lose to a greater or less extent their S-shape." The tubule here modeled appeared to be intact throughout, though at this stage they are so difficult to follow that errors are quite possible, either in introducing a discontinuity or in filling an actual gap. The tubule chosen for modeling

1 This statement is found on page 829 of Bronn's Klassen und Ordnungen des Thier-Reichs, Bd. 6, Abth. 4, Vögel, von H. Gadow and E. Selenka. It appears to be in Gadow's portion of the work and is wrongly credited to Selenka by Weber, who among others, accepts it. See Weber, In Schwalbe's Archiv, 1897, page 621. 
is the twenty-eighth to enter the Wolffian duct on the left side; three more occur below it. Of these thirty-one tubules, the anterior are extensively degenerated, and lend no support to MacCallum's statement that "the degeneration of tubules progresses from the posterior end of the organ forward." On the contrary, a posterior tubule was chosen as probably typical of those most highly developed. Its actual length, as calculated from the model, is $1.5 \mathrm{~mm}$.- - nearly twice that of the preceding stage. The portion $C$, with its glomerular end bent upward or anteriorly, lies within the concavity of portion $Z$, which also extends upward to enter the Wolffian duct. This disposition of parts would produce the result observed by MacCallum when injecting the tubules of the pig. The fluid could be seen, through the thin overlying tissue, to pass from the Wolffian duct into the tubules and to flow through them around the lateral surface of the gland to the dorsal border. At a certain place, in tubules just beneath the superficial ones, the fluid could be seen to run in the opposite direction.

Although the tubule at this stage is of a simpler pattern than the double spiral, and consists of two rather than three segments, the remains of the middle or U-portion can be identified. A narrowing of the tubule marks the place where the $U$ begins, and it proceeds around the bend into $Z$, where it ends without definite boundary. An interpretation of the model in terms of the double spiral is shown in figure 9, and the group of figures ( 5 to 9 ) presents the evolution of a human tubule from a length of $0.3 \mathrm{~mm}$. to $1.5 \mathrm{~mm}$. without the formation of capricious folds, but according to a very simple law.

That the Wolffian body of the pig is more highly developed than in man is shown in several ways, but very clearly in the greater length of its tubules. The length in a $6-\mathrm{mm}$. pig, as calculated from a single model, is $1.9 \mathrm{~mm}$., and at $20 \mathrm{~mm}$. it has increased to $13.5 \mathrm{~mm}$. ; that is, the tubules of the pig are found to be from six to eight times longer than those of man, and more extensive coiling may be anticipated. The typical double spiral is formed early in the pig, as already shown in figure 4, from an embryo of $4.5 \mathrm{~mm}$. A somewhat later stage was modeled in 
1909 by Dr. F. T. Krusen, in connection with the undergraduate course in embryology given by Professor Minot and assistants. This model, duly catalogued and placed in the Harvard Collection, has apparently never before been utilized. Its essential features are shown in figure 10, in which such slight displacements have been made as are necessary for following the coils easily. In this tubule, from a $6-\mathrm{mm}$. pig, the segment $U$ is directed toward the concavity of $C$, and a new loop, $V$, intervening between $U$ and $Z$, has appeared, pointed toward the concavity of the $U$; $Z$ is without special features. This pattern might be regarded as a casual form were it not duplicated in MacCallum's figure, here reproduced reversed as figure 11.

MacCallum described his figure as a "diagrammatic reconstruction of Wolffian tubules" from a pig embryo of $8 \mathrm{~mm}$., and he presented it as applying to "a number of tubules." Referring to an older embryo, he writes: "Special names might be given to the different parts of the tubule, but until their significance is more definitely known this could be of little value. There is, however, a very distinct division into a secretory and a conducting part." But without discussing relative values of morphological and physiological subdivisions, it is clear that we stand on firmer ground in describing the course of the tubule than in assigning a functional significance to its various bends. It is unfortunately true that the limits of the secretory portion in the pig remain unknown and MacCallum did not succeed in defining them. He put together the upper part of $C$ (in fig. 11) and the adjacent limb of the $U$ as the 'secretory loop,' and this loop forms the only subdivision of the tubule which he recognized. But judged by its large diameter in figure 10, the remainder of the $U$ is also secretory; whereas in man none of the part $U$ was of the same nature as $C$, and the latter was certainly secretory. Whether the subdivisions here imposed upon MacCallum's figure are profitable or not may be questioned, but they enable one to sketch quickly the course of the Wolffian tubule not only in the young embryos now considered, but also in older ones where previously no description was attempted. 
For permission to make and publish figure 12, the writer is under special obligation to Dr. Frank H. Rose, who made the model, and to Prof. Franklin P. Johnson, who directed Doctor Rose's study in the University of Missouri. This model of a tubule in a $20-\mathrm{mm}$. pig is incidental to a comprehensive study of that embryo, being made by Professor Johnson and his pupils, and later to be published in detail. The simplified sketch, showing all the essential bends and loops in this long and involved tubule, may readily be compared with the figures of the earlier stage already discussed. From the glomerular capsule, with initial kinks, the portion $C$ sweeps in a well-rounded curve to the dorsal border, and forms a $U$ in the concavity of the $C$ and a $V$ in the concavity of the $U$, with a final sweeping curve enclosing them all-the portion $Z$.

This model again accords, in surprising detail, with MacCallum's figure of the tubule from a much larger pig, measuring $80 \mathrm{~mm}$. Neither the length of the tubule nor the magnification of the figure is stated, but the tubule, here shown reversed in figure 13 , is evidently much longer than in the preceding stage. A secondary coil has appeared along the portion $U$ and another in connection with $V$. The coil in the descending limb of the $U$ chances to be comparable with a kink in figure 12 , but the constancy of this feature remains to be determined. The new loop in segment $V$, which may or may not correspond with a slight bend in the tubule at $20 \mathrm{~mm}$., is not directed toward the apex of the $V$; if it should become so, it would carry the evolution of the characteristic pattern one step further than has yet been observed.

Finally, it may be repeated that the total number of tubules studied is small for drawing general deductions. But the close agreement in the findings of independent observers and the absence of a single aberrant form from the group carefully modeled are evidence in favor of the interpretation presented. In these models an easily recognized pattern exists, much more complicated than the double-spiral form from which it springs. 


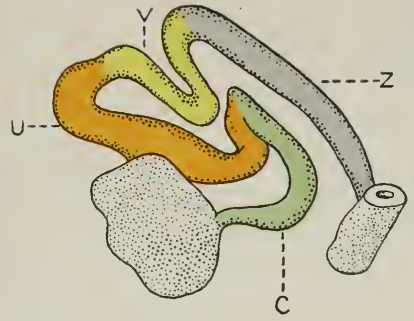

Jig. 10 .

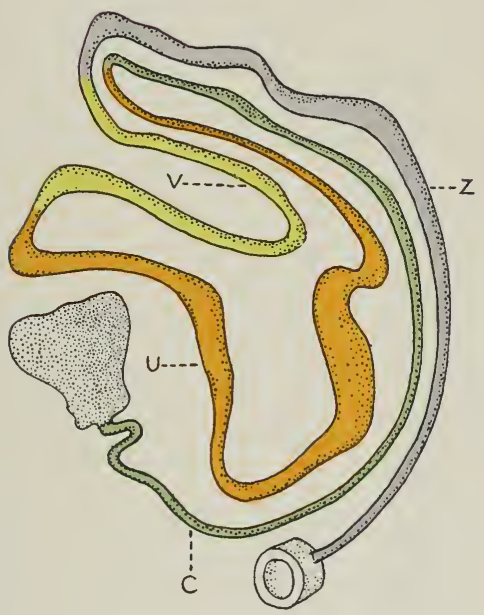

Fig. 12 .

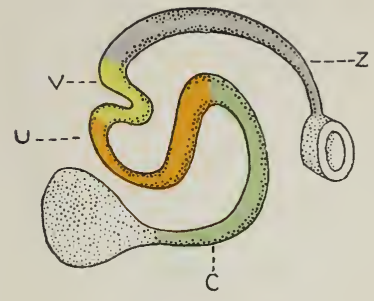

$\mathscr{F}_{29.11 .}$

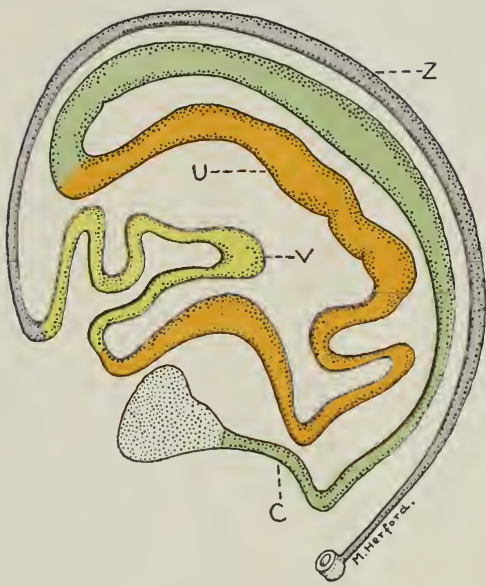

$F_{i g .13 .}$

Figs. 10 to 13 Wolffian tubules of pig embryos. Small irregularities in the models have been omitted, and the coils have been slightly spread apart to display the course of the tubules. Colors have been used to mark out the segments $\mathrm{C}, \mathrm{U}, \mathrm{V}$, and $\mathrm{Z}$, thus demonstrating more clearly the type pattern.

Fig. 10 Model by F. T. Krusen. Pig embryo of $6 \mathrm{~mm}$. Harvard Embryological Collection, series 918.

Fig. 11 Reversed drawing of MacCallum's 'diagrammatic reconstruction.' Pig embryo of $8 \mathrm{~mm}$. Am. Jour. Anat., vol. 1, p. 251, fig. 7.

Fig. 12 Model by F. H. Rose. Pig embryo of $20 \mathrm{~mm}$. University of Missoui Embryological Collection, ro. 1.28.

Fig. 13 Reversed drawing of MacCallum's 'wax reconstruction.' Pig embryo of $80 \mathrm{~mm}$. Am. Jour. Anat., vol. 1, p. 252, fig. 8 . 



\section{LITERATURE CITED}

Bremer, J. L. 1911 Morphology of the tubules of the human testis and epididymis. Am. Jour. Anat., vol. 11, p. 404.

FeLix, W. 1912 The mesonephros. Human embryology, edited by Keibel and Mall, vol. 2, p. 807 .

Gadow, H. 1891 Vögel. Bronn's Klassen und Ordnungen des Thier-Reichs. Bd. 6, Abth. 4, Th. 1, S. 829.

KöLliker, A. 1879 Entwicklungsgeschichte des Menschen. Zweite Auflage, S. 944.

Kollmand, J. 1898 Lehrbuch der Entwickelungsgeschichte des Menschen, S. 398-399.

LineBack, P. E. 1916 The development of the spiral coil in the large intestine of the pig. Am. Jour. Anat., vol. 20, pp. 488-489.

MaCCAllum, J. B. 1902 Notes on the Wolffian body of higher mammals. Am. Jour. Anat., vol. 1, pp. 250-254.

Meyer, H. 1890 Die Entwickelung der Urnieren beim Menschen. Arch. f. mikr. Anat., Bd. 36, S. 161.

Minalkovics, G. V. voN 1885 Untersuchungen über die Entwickelung des Harn- und Geschlechtsapparates der Amnioten. Internat. Monatschr. f. Anat. u. Physiol., Bd. 2, S. 76-79.

Minot, C. S. 1892 Human embryology, p. 239.

Nicolas, A. 1891 Contribution à l'étude des cellules glandulaires. I. Les éléments des canalicules du rein primitif chez les mammifères. Extrait du Journ. internat. d'Anat. et de Physiol., T. 8, p. 94 (of the reprint)-"Conclusions."

Schreiner, K. E. 1902 Über die Entwicklung der Amniotenniere. Zeitschr. f. wiss. Zool., Bd. 71, S. 96.

Tномpson, D. W. 1917 On growth and form. Cambridge University Press.

WeBer, S. 1897 Zur Entwicklungsgeschichte des uropoetischen Apparates bei Säugern. Morphol. Arbeiten.Bd. 70, S. 621.

Winiwarter, H. von 1910 La constitution et l'involution du corps de Wolff. Arch. de. Biol., T. 25, p. 184.

\section{ADDENDUM}

The foregoing account pertains only to mammals but it may be of interest to compare the models of the Wolffian tubules in pig embryos with those of the corresponding structures in adult amphibians. For this purpose two figures are available, by Nussbaum and Huber respectively. Nussbaum (Arch. f. mikr. Anat., 1886, Bd. 27, Taf. 23, Fig. 28) shows a mesonephric tubule isolated by maceration from the kidney of Rana esculenta. Any subdivision into C, U, V and $\mathrm{Z}$ portions seems impossible. Huber (Anat. Rec., 1917, vol. 13, p. 310) presents a wax reconstruction of a tubule from Rana catesbiana, which has 'many points of similarity' to Nussbaum's figure, and yet, notwithstanding many secondary convolutions, may readily be resolved into the pattern in question. Further study is needed to show whether this interpretation of the model is of any real significance. 




\section{THE AMERICAN JOURNAL OF ANATOMY}

VOLUME 26, NUMBER 3, JANUARY 15,1920

\section{CONTENTS}

Leslie B. Arey. The origin, growth, and fate of osteoclasts and their relation to bone

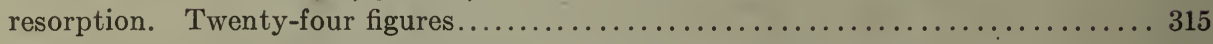

S. SAGUChI. Studies on the glandular cells of the frog's pancreas. Five plates........ 347

Frederic T. Lewis. The course of the Wolffian tubules in mammalian embryos. Thir-

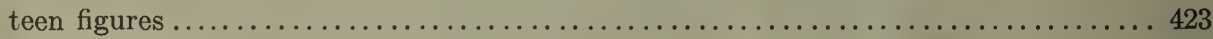

William H. F. Addison. Histological study of the spleen of the rabbit under heightened phagocytic activity. Six figures (one plate) $\ldots \ldots \ldots \ldots \ldots \ldots \ldots \ldots \ldots \ldots \ldots \ldots \ldots$ 